\title{
Filter paper method to determine the water retention curves for mortar and cement samples
}

\section{Utilização do método do papel-filtro para determinação de curvas de retenção de água em argamassas e concretos}
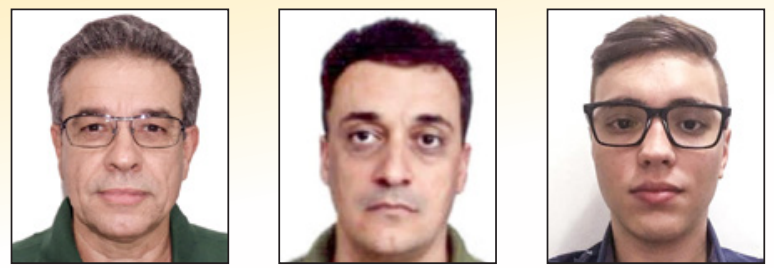

J. M. L. VILASBOAS a josemarcilio@oi.com.br

S. L. MACHADO b smachado@ufba.br

S. A. PINTO b silas.andrade14@gmail.com

\begin{abstract}
This study deals with the application of the filter paper method to determine water retention curves for mortar and concrete samples. A water retention curve exhibits the relationship between water content and energy state in interstitial water, normally expressed as a negative value when compare to normal conditions of temperature and pressure, being referred to as suction. Considering the water retention curve as a basic characterization tool for unsaturated soils, its usage in the engineering field concerning most of the construction materials remains as a pending task. However, stating that not only permeability, but also the water retention curve performs a significant role for water and soluble substances flow through a material's pores makes this observation essential for life-span estimation in cases like reinforced-concrete structures. This research paper offers results for water retention curves obtained in mortar and concrete samples. The experimental curves went through a fitting adjustment process using Van Genutchen's [1] model, showing consistency with the obtained results. Furthermore, the water/cement mix ratio does not indicate or suggest a direct influence for water retention curves.
\end{abstract}

Keywords: water retention curves, suction, filter paper, concrete, mortar.

\section{Resumo}

Este trabalho trata do uso da técnica do papel-filtro para a obtenção, em laboratório, de curvas de retenção de água em corpos de prova de argamassa e concreto. A curva de retenção correlaciona o conteúdo de água de meios porosos com o estado de energia da água intersticial, que em condições não saturadas (vazios não totalmente preenchidos por água) é normalmente negativo em relação às condições normais de temperatura e pressão, sendo denominado de sucção. Embora possa ser descrita como uma ferramenta básica de caracterização de solos não saturados, o uso da curva de retenção em concretos e argamassas ainda não foi introduzido na prática da engenharia para a maioria dos materiais de construção. Pode-se dizer, contudo, que não somente a permeabilidade, mas também a curva de retenção desempenha um papel fundamental no fluxo de água e substâncias solúveis pelos poros do material, sendo imprescindível o seu conhecimento, para, por exemplo, estimar a vida útil das estruturas de concreto armado. São apresentados resultados de ensaios de sucção total pelo método do papel-filtro, os quais permitiram determinar curvas de retenção para corpos de prova de concreto e argamassa. Estas curvas foram ajustadas segundo o modelo de Van Genutchen [1], o qual apresentou boa aderência aos valores experimentais. Não foi possível observar influência significativa da relação água-cimento nas curvas de retenção obtidas.

Palavras-chave: curva de retenção, sucção, papel-filtro, concreto, argamassa. 


\section{Introduction}

When simulating water flow processes or the transportation of soluble substances in water, it is not only necessary the comprehension of the saturated permeability within the medium, but also its water retention curves and hydraulic conductivity. A water retention curve relates water content for a porous media with its energy state in interstitial water. This energy state, generally represented by negative pressures (due to the atmospheric pressure standard) for water held in the material's pores, results in a phenomena such as capillarity and adsorption, which are negative pressures often referred as suction. Although, often used as a basic characterization tool for unsaturated soils, the usage and procurement of water retention curves in mortars and concrete remains unexplored for engineering practices for most construction materials. In addition, the structure's surrounding conditions influence the results. Thus, a previous suction understanding is essential, as well as, its water content variation due to evaporation, when performing an analysis. For example, analyzing the soluble substances penetration such as chlorides in mortar and concrete sections while expose to maritime aggressiveness.

The suction for porous media is an energy state within interstitial water, associated with its water retention capacity, normally expressed in terms of hydraulic head (energy by weight) or pressure (energy by volume). When placing free water into a porous medium, such as mortar or concrete, the fluid remains in retention or becomes absorbed, until all of the empty spaces fill with water (condition for saturated porous medium). In order to get this water removed from the porous medium, energy is required affecting the material's retention forces, that originate, mainly, from the capillarity, absorption and osmosis phenomena. The drier concrete and mortars are the greater its suction becomes, as a result during the drying process, water stores within the smallest pore diameters and the solid's particle surface, building a layer of absorbed water. Soil physics determines, on a regular basis, a medium's retention curve, when obtaining a soil's suction limits that needs to be prepared for cultivation of a specific crop: field capacity and wilting point. For field capacity (nearly $30 \mathrm{kPa}$ of suction), interstitial water begins to flow when submitted to the gravitational potential, in such case that an extra water addition will only cause water infiltration, besides the rhizomes of the used crop. In the other hand, wilting capacity (equal to a $1500 \mathrm{kPa}$ suction), admits that the existing water in soil becomes unavailable for plants.

In the geotechnical field, there are several processes used when determining the water retention curve. According to Machado and Presa [2], there is a prevailing tendency for combined technique application during the procurement of the water retention curve. For example, the suction plate's usage (water pressure, $u_{w}<0$ and air pressure, $u_{a}=0$ ) for low suction values (proximate to $70 \mathrm{kPa}$ ), the pressure chamber for intermediate values (up to $1500 \mathrm{kPa}$ ) and the filter paper method for high suction values. Table 1 presents typical usage intervals for different techniques of imposition/ suction measurement.

In the same way as in soil mechanics, the two main components for water retention in concrete are capillarity and absorption. These components decrease the fluid's specific energy in such a way that when pores undergo unsaturated conditions, the water's interstitial pressure becomes smaller than the atmospheric pressure. This explains the capillarity ascension phenomenon. Ascension means rising into higher elevations, implicating that the fluid moves towards a higher potential gravitational position. Taking into account that every fluid can only flow from a higher energy potential to a lower one, water pressure within unsaturated medium will always be smaller than atmospheric pressure, considering Bernoulli's equation variables. Frequently, it is common to use the interstitial or matrix concept to work with positive values, subsequent only from the resulting difference between the air (normally atmospheric) and water pressure values, caused by the capillarity and absorption phenomena, i.e.: suction $=u_{a r}-u_{w}$, where $u_{a r}$ corresponds to the air phase pressure and $u_{w}$ to the water phase pressure.

The NBR 9779 [3] suggests the capillary ascension method as a procedure to determine water absorption for mortars and harden concrete. In addition, stating the requirement of a representative sample of at least three test subjects, permitting them to molded or extracted from the structure. However, the capillary ascension effect observed is not only an outcome caused by the joined interactions between capillary suction and absorption when tempting to reduce the energy within interstitial water, but also from the permeability increase against water due to the sample's initial water content increase during the whole test completion.

\section{Table 1 - Some of the used techniques for measurement/imposition soil suction}

\begin{tabular}{|ccc|}
\hline Technique & Suction parameter measured & Measurement range $(\mathbf{k P a})$ \\
\hline Paper filter & Total and matrix & $10-30000$ \\
\hline Thermal conductivity detector & Matrix & $0-400$ \\
Tensiometer & Matrix & $0-70$ \\
Microtensiometer & Matrix & $0-1500$ \\
Hilf axis techniques & Matrix & $0-1500$ \\
Vapor equilibrium & Matrix & $0-1500$ \\
Vapor equilibrium & Total & $3000-3,0 \times 10^{5}$ \\
Pressure plates & Matrix & $0-70$ \\
Psychrometer & Total & $500-8000$ \\
\hline Source: Machado and Presa (2) adaptation. & & \\
\hline
\end{tabular}


Although, it is not a common practice in the concrete technological field, the ideal water flow modeling for concrete, under unsaturated conditions, is the separate procurement of retention curves and hydraulic conductivity. This differentiation allows water flow modeling within the material's interior, , as long as the acceptable surrounding conditions are adopted, which can be used, for example, to predict the time for external chloride arrival within the rebar structure in reinforced concrete components, creating satisfactory conditions to burst the corrosion process.

As previously mentioned, when fluid content within any porous medium, generally represented by the gravimetric or volumetric water content, modifies, it takes place to a variation in the fluid's energy state, as well as its mobility ease within the interstices. As water volume decreases, a "fluid section" within the material's empty spaces becomes gradually smaller. Therefore, during the drying process, there is a certain period of time, where continuity amongst the fluid particles can be interrupted, point where permeability is practically nullify. This way, in the case for unsaturated porous media, it is common to reference in terms of hydraulic conductivity, in which permeability values are normally linked to the fluid content or to the intrinsic energy state (normally given by the suction value) of the medium. However, there is not a clear consensus amongst the specialized literature available, whereas the permeability term in this research paper refers to the function value of the hydraulic conductivity under saturated conditions for a material.

Consequently, the water retention curve is referred to as the existing relationship between the medium's water content and the energy state within interstitial water. Figure 1 presents typical water retention curves for sandy and clayey soils, according to Presa [4]. In this figure, suction values are located in the ordinate, in terms of logarithmic expression for hydraulic load (PF), and the water content values are located in the abscissa, in terms of gravimetric humidity. Often, research studies related to the soil physics field apply this model, although in this particular case the volumetric water content is applied.

As observed on the above figure, the water retention curve depends on the uninterrupted course (drying, wetting or mixed) followed during the test implementation, phenomenon known as hysteresis. Different are the causes for this phenomenon, for instance, irregular geometry in pores linked through small openings, contact angle effect that varies in terms of the uninterrupted course, the incidence of prisoned air bubbles that influence the wetting curve, and the volume variations suffered due to expansion and retraction. Therefore, during the water content redistribution process, different values are found for the same soil upon suction equilibrium conditions, according to Presa [4].

There is no background information found on literature concerning the procurement of water retention curves for concrete through the paper filter method. Furthermore, few curve data is available, regardless of any procedure application. Relating to the applied methods for curve exemplification, those proposed by Van Genuchten [1], equation 1, and Fredlund and Xing [5], equation 2, are most common for geotechnical usage. In these equations, a $\left(\mathrm{kPa}^{-1}\right), \mathrm{a}(\mathrm{kPa}), \mathrm{n}$ and $\mathrm{m}$ are fitting parameters, $\theta_{\text {sat }}$ corresponds to the volumetric saturated water content (equal to the medium's porosity), $\theta_{r}$ to residual water content (where the interstitial water becomes irregular) and e corresponds to the Napierian base logarithm $(e=2,718)$. Both equations show similarities, such as, water content or suction values, needing a great increase of suction or energy for an extra drying of the medium. $\theta_{\mathrm{r}}$ and $\psi_{\mathrm{r}}$, are water
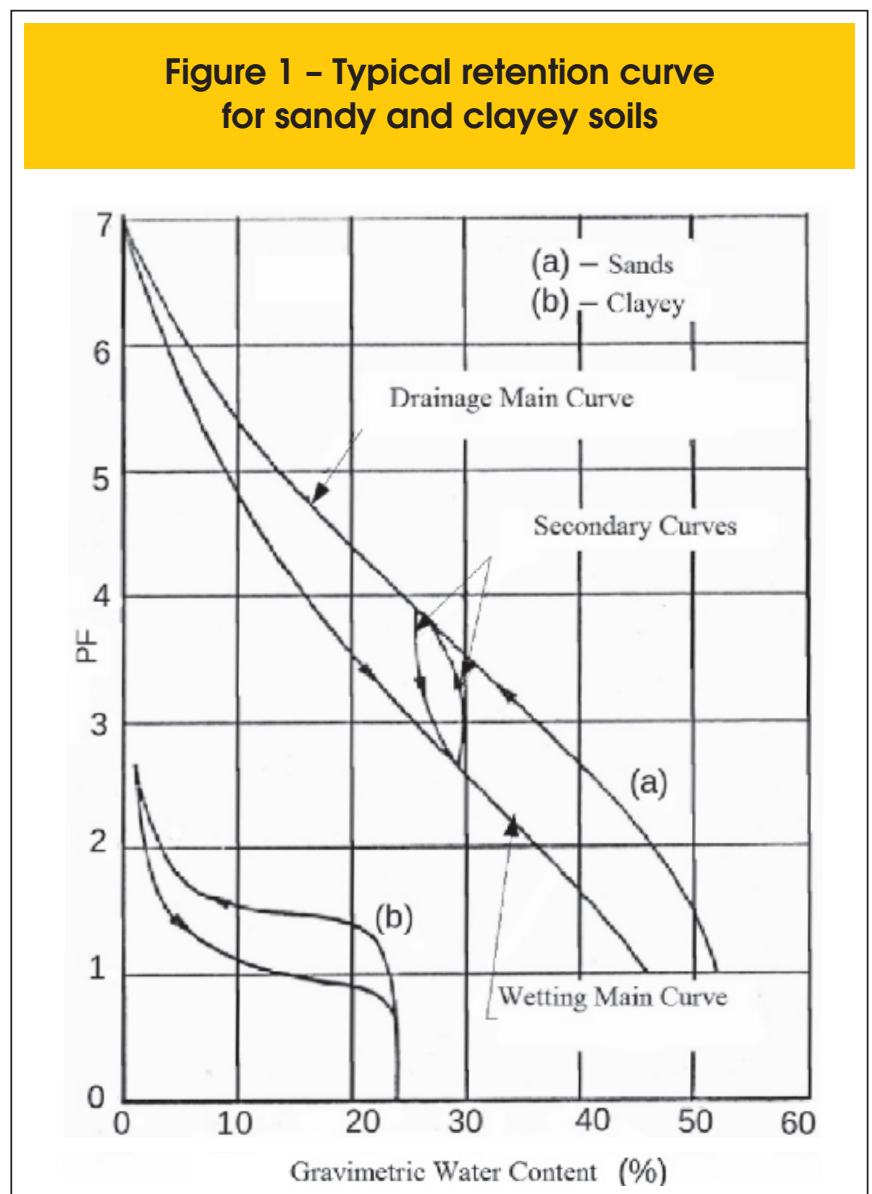

Source: Presa (4)

content and residual suction values, respectively. Van Genuchten's proposed equation offers a great advantage due to its simplicity, in contrast to the equation proposed by Fredlund and Xing [5], which enables the retention curve representation of the medium until complete drying, taking place when a suction value is proximate to $1 \times 10^{6} \mathrm{kPa}$, according to these authors.

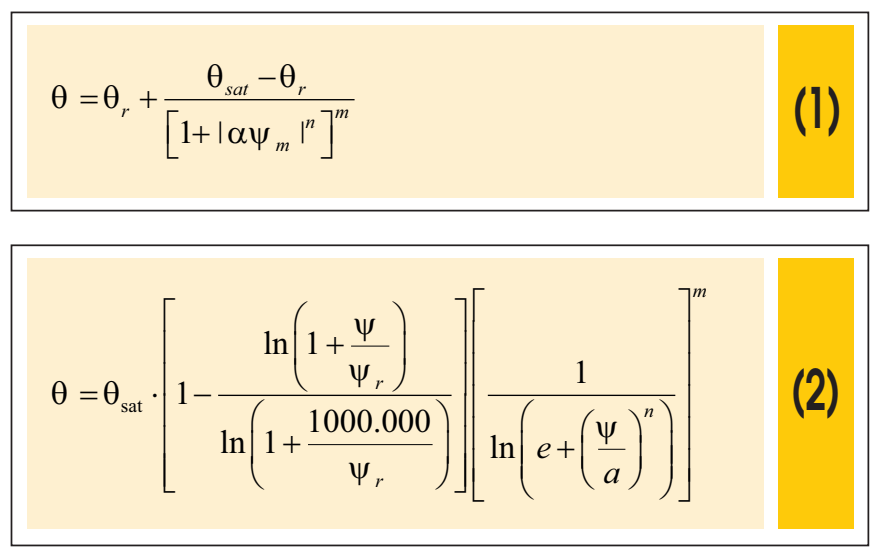

Since water content affects the ease in which water flows through the medium, the medium's hydraulic conductivity curve is needed to model the substance's flow as well. Thus, permeability values 
Table 2 - Fresh-state mortar composition and specifications

\begin{tabular}{cccccccc} 
Trace & $\begin{array}{c}\text { Proportion } \\
\text { (cement: sand), } \\
\text { in weight }\end{array}$ & $\begin{array}{c}\text { Water/ cement } \\
\text { ratio } \\
\text { w/c }\end{array}$ & $\begin{array}{c}\text { Cement } \\
\text { consumption } \\
\left(\mathrm{kg} / \mathrm{m}^{3}\right)\end{array}$ & $\begin{array}{c}\text { Consistency } \\
\text { index } \\
(\mathrm{mm})\end{array}$ & $\begin{array}{c}\text { Porosity } \\
(\%)\end{array}$ & $\begin{array}{c}\text { Density } \\
\left(\mathrm{kg} / \mathrm{m}^{3}\right)\end{array}$ \\
\hline T-1A & $1: 4,167$ & 0,650 & 368 & 167 & 28,5 & 1897 \\
T-1B & $1: 3,690$ & 0,650 & 397 & 223 & 29,9 & 1890 \\
T-2A & $1: 3,377$ & 0,550 & 441 & 162 & 27,0 & 1954 \\
T-2B & $1: 2,968$ & 0,550 & 476 & 230 & 27,6 & 1921 \\
T-3A & $1: 2,577$ & 0,450 & 552 & 161 & 23,0 & 2056 \\
T-3B & $1: 2,247$ & 0,450 & 592 & 232 & 25,0 & 2026 \\
\hline
\end{tabular}

are expressed in terms of suction or the fluid content of interest. Therefore, considering the Mualem [6] model for $k(\theta)$ prediction, Van Genuchten [1], and simplification of the expression, $\mathrm{m}=1-\frac{1}{n}$, the following equation is proposed for hydraulic conductivity prediction.

$$
k(\theta)=k_{\text {sat }} \cdot \omega^{p}\left[1-\left(1-\omega^{\frac{1}{m}}\right)^{m}\right]^{2}
$$

where:

$\omega$, effective soil saturation, given by equation 4 ;

$\mathrm{k}_{\text {sat }}$, hydraulic conductivity for a saturated-pore medium;

$p$, empiric parameter by Mualem [6], proximate to 0,5 for most soils (no values found for concrete material).

$$
\omega=\frac{\theta-\theta_{r}}{\theta_{\text {sat }}-\theta_{r}}
$$

\section{Material sand methods}

\subsection{Experimental determination for the suction characteristic curve}

The method chosen for the retention curve determination for mortar and concrete samples, corresponds to the established Brazilian standard technical norm, ASTM D5298 [7], on the subject of paper filter practice, which considers suction values between the range of 30 to $30.000 \mathrm{kPa}$, as stated by Silva [8].Tables 2 and 3 display the mortars and concrete sample traces produced during the two experimental stages. During the first stage, mortars produced from experimental mixtures have the criteria from different research studies to regulate the water/cement ratio, obtaining mixtures with different consistency indexes, $(165 \pm 5) \mathrm{mm}$ and $(225 \pm$ 10) $\mathrm{mm}$, which consequently lead to diverse cement consumption. Therefore, mortars with water/cement proportions of $0.45,0.55$ and 0.65 were prepared, having 4 cylindrical test subjects for each mixture with $50 \mathrm{~mm} \times 100 \mathrm{~mm}$ dimensions producing a total of 24 test subjects. The procedure adopted is described in the previously mentioned norm [9]. After each test subject hardened, 8 different sections were cut, discarding the edges, and submitted to the suction test through the paper filter method.

During the second stage, concrete samples of a single consistency were produced, $(140 \pm 20) \mathrm{mm}$ reduction, as well as water/cement mix proportions equal to $0.45 ; 0.55$ and 0.65 . Then, 4 cylindrical test subjects were molded for each trace with $100 \mathrm{~mm} \times 200 \mathrm{~mm}$ dimensions, resulting in 12 test subjects in total. The molding and curing procedure comply with the Brazilian standard technical norm [10].The test subjects were cut into 8 sections for each trace, discarding the edges, and submitted to the suction test through the paper filter method.

\section{a) Test description}

Current soil techniques and standard procedures established by the technical norm [11] were followed to help develop a standard

\section{Table 3 - Fresh-state concrete mix composition and specifications}

\begin{tabular}{cccccccc} 
Trace & $\begin{array}{c}\text { Proportion } \\
\text { (cement: sand) } \\
\text { in weight }\end{array}$ & $\begin{array}{c}\text { Water/ cement } \\
\text { ratio } \\
\text { w/c }\end{array}$ & $\begin{array}{c}\text { Cement } \\
\text { consumption } \\
\left(\mathrm{kg} / \mathrm{m}^{3}\right)\end{array}$ & $\begin{array}{c}\text { Consistency } \\
\text { index } \\
(\mathrm{mm})\end{array}$ & $\begin{array}{c}\text { Porosity } \\
(\%)\end{array}$ & $\begin{array}{c}\text { Density } \\
\left(\mathrm{kg} / \mathrm{m}^{3}\right)\end{array}$ \\
T- 4A & $1: 1,800: 3,390$ & 0,650 & 337 & 150 & 18,82 & 2192 \\
T- 5A & $1: 1,368: 2,870$ & 0,550 & 405 & 145 & 18,26 & 2207 \\
\hline T- 6A & $1: 0,937: 2,349$ & 0,450 & 497 & 135 & 15,71 & 2276 \\
\hline
\end{tabular}


procedure from the paper filter application when determining suction values for mortars and concrete. The paper filter method is based in the porous media absorption capacity or water loss (or other fluid), when in direct or indirect contact with the fluid, in a closed environment, at constant pressure and temperature until energy equilibrium is reached. When this happens, the humidity values of the porous medium (mortar or concrete) and the paper filter are typically different; however, both have the same suction value. The energy equilibrium is reached, supposedly, when no water is transferred to the paper filter (element weight consistency).

There are two ways to carry on the procedure: direct contact between the paper filter and the sample, and no contact between these two. When there is no direct contact, the water exchange between both takes place through water vapor. In this case, no water exchange occurs for dissolved fluids in the sample's interstitial water, finding the value of total suction (osmotic + capillary + adsorption). The conditions created within the container act as a semi-permeable membrane, allowing water exchange to occur only through the vapor inside, when dealing with non-volatile solutes. Energy states within the sample's water content, paper filter and air, within the impervious sealed container regulated by the relative humidity, are different during the beginning of the procedure. These energy gradients encourage water flow. Finally, same suction values become in a state of equilibrium, within the whole system, encouraged by the water contents in the sample, paper filter and the air (relative humidity).

When the paper filter comes into direct contact with the sample, water exchange occurs in a liquid state and the type of suction measured in this case, is its matrix suction (capillarity + absorption), originated from the equilibrium state caused by the concentration of solutes inside the medium.

During this research study, total suction values were measured (no contact), placing the paper filter next to the test subject, seeking to minimize the air volume between both materials within the container and decreasing the required time for the system's equilibrium achievement.

Supplementary measures were also taking in place due to vapor condensation in the container's interior, which can origin measurement errors when water drops fall into the paper. In addition, considerations took place to avoid the paper filter's contamination, like the use of gloves and tweezers for the operator, specifically when manipulating samples and the whole testing equipment. A weightmeasuring scale with $0,001 \mathrm{~g}$ minimum precision needs to be use in order to obtain the paper filter weight.

Before each procedure's implementation, all samples were initially saturated and dried to air until the achievement of the required water content values, $w$. Consequently, for every test a drying pattern was followed, avoiding hysteresis effects in the retention curve. After this stage, the system (test subject and paper filter) was put inside a container, sealed with tape (see figure 2). Finally, the use of PVC rings to avoid direct contact between the paper filter and the sample (test subject).

Preliminary tests performed, verified the required time for the system's equilibrium achievement. This was achieved by opening the container periodically to measure the sample's weight. Afterwards, at least a 15 day time period was followed, sealing and placing the containers inside a temperature-controlled room $\left(20^{\circ} \mathrm{C}\right.$ with \pm $0.5^{\circ} \mathrm{C}$ variations), acclimatized within a Styrofoam box.

\section{Figure 2 - Sealed container with paper filter, PVC rings and the test subject (sample)}

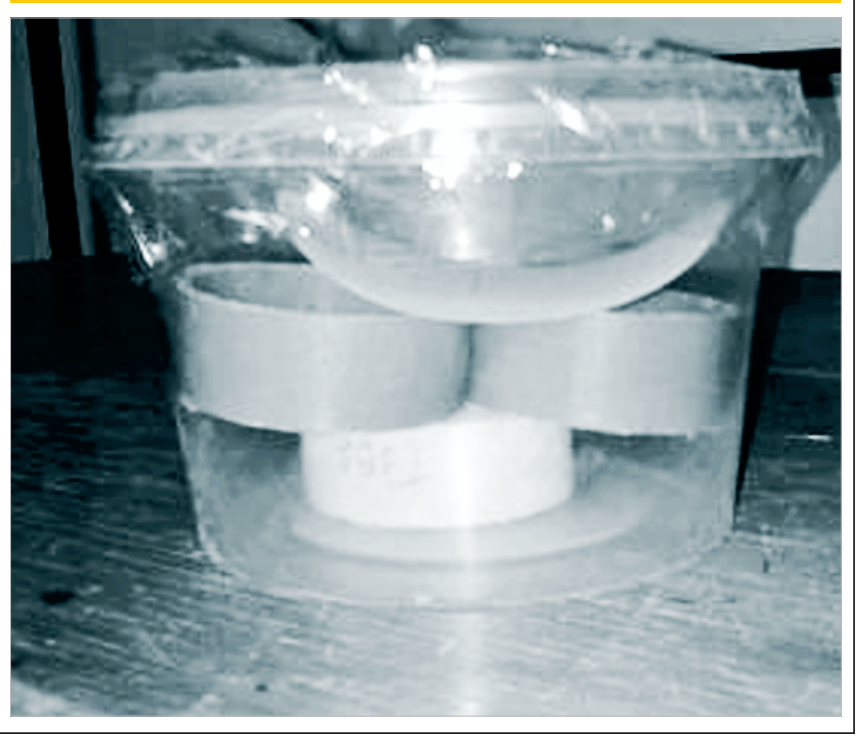

After achieving suction equilibrium amongst the container components, the sample and paper filter are weighed. A discrepancy, during the test, was noticed when each paper filter was dried inside the oven, before placing it inside the container next to the test subject. The experimental results were not being compatible with the calibrations curves proposed by Chandler and Gutierrez [11]. For that reason, the paper filter drying should be avoided beforehand. The paper filter's weight is a critical aspect during the test's implementation. The container must be opened to rapidly remove the paper filter with the aid of tweezers, located within the previously weighed capsule, obtaining the weight of both components with the appropriate scale. Afterwards, both components are taken into the oven. The delay time during this procedure can influence the paper filter to absorb water from the atmosphere, modifying the experimental values.

In addition, the capsule's weight determination can be consider after the drying process due to small dust particles initially located within the capsule, volatized in the oven, altering the experimental values. The drying procedure for mortars or concrete samples can be done in a conventional way.

After obtaining before and after measures, paper filter weights for each sample, as well as the material's physical properties, the following parameters are determined: the water content and dry weight readings within the paper and test subject.

Based on the materials' phase relationship and the experimental data, the paper filter's moisture content (\%) is determined, as well as its suction value, using equations 5 and 6 proposed by Chandler and Gutierrez [11], assuming that the value is the same for the sample or test subject.

Each sample tested provides a point (moisture, suction) for the water retention curve, considering that 8 samples (sections) were obtained for each mortar or concrete trace. Consequently, the water retention curve for each material was determined with the different moisture content values obtained during each test. 

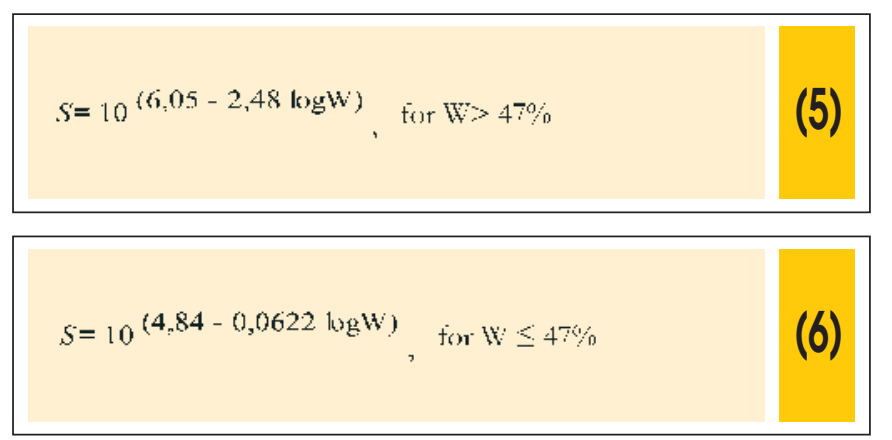

where:

w, the paper filter's moisture content (\%)

$\mathrm{S}$, is the suction value ( $\mathrm{kPa}$.)

In this study, Van Genutchen's [1] equation was used to adjust the experimental retention curve. The equation presents the samples' water content in terms of volumetric water content, $\theta$, being the ratio between the water volume and the total volume. Therefore, the materials' (mortar and concrete) density values were needed, in order to convert the gravimetric water content values into volumetric water content.

\section{Results and analysis}

The total suction results obtained through the paper filter method for each mortar and concrete sample execute dare shown in Tables 4 and 5, respectively. These tables show the final water content values for each material, as well as the equilibrium suction values calculated with equations 5 and 6 , using the paper filter's final moisture. Remarking that only satisfactory values from test results are offered in both tables.

Figures 3 and 4 present the obtained results for the water retention curves for mortar and concrete samples, respectively. Noting, primarily in the case of mortar samples, that the obtained values are proximate from one another. This can suggest that the usage of different values of the water/cement mixture ratio does not modify the medium's micro-pore distribution. In the particu-

\begin{tabular}{|c|c|c|c|c|c|c|c|c|}
\hline \multicolumn{9}{|c|}{ Table 4 - Suction test results for mortar test subjects } \\
\hline & \multirow{2}{*}{\multicolumn{2}{|c|}{ Data }} & & \multirow{2}{*}{$\begin{array}{l}\text { Paper filter's } \\
\text { gravimetricwater } \\
\text { content (\%) }\end{array}$} & \multicolumn{2}{|c|}{$\begin{array}{l}\text { Test subject's gravimetric water } \\
\text { content }(\%)\end{array}$} & \multirow{2}{*}{$\begin{array}{l}\text { Suction } \\
\text { (kPa) }\end{array}$} & \multirow{2}{*}{$\begin{array}{c}\text { Test subject's } \\
\text { volumetric } \\
\text { water } \theta(\%)\end{array}$} \\
\hline & & & & & Before & Affer & & \\
\hline & \multirow{10}{*}{$\begin{array}{l}\qquad 8 \\
0 \\
11 \\
0 \\
0 \\
0\end{array}$} & \multirow{4}{*}{ 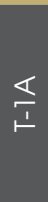 } & \multirow{4}{*}{ 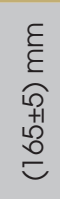 } & 13,32 & 3,22 & 3,10 & 10264,37 & 6,19 \\
\hline & & & & 25,36 & 7,26 & 6,83 & 1829,75 & 13,64 \\
\hline & & & & 28,41 & 8,13 & 7,69 & 1183,56 & 15,35 \\
\hline & & & & 34,26 & 9,09 & 8,48 & 511,55 & 16,94 \\
\hline & & \multirow{6}{*}{$\stackrel{\infty}{\leftarrow}$} & \multirow{6}{*}{ 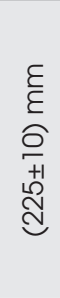 } & 10,71 & 3,10 & 3,01 & 14925,79 & 6,02 \\
\hline & & & & 19,02 & 5,58 & 5,26 & 4541,30 & 10,50 \\
\hline & & & & 23,61 & 7,20 & 6,75 & 2353,27 & 13,48 \\
\hline & & & & 25,99 & 8,14 & 7,65 & 1671,91 & 15,27 \\
\hline & & & & 35,63 & 10,45 & 9,80 & 420,41 & 19,57 \\
\hline & & & & 36,36 & 11,54 & 10,79 & 378,60 & 21,55 \\
\hline$\frac{5}{\bar{d}}$ & \multirow{10}{*}{$\begin{array}{l}\llcorner \\
\llcorner \\
0 \\
0 \\
11 \\
0 \\
0\end{array}$} & \multirow{7}{*}{$\underset{亡}{\overleftarrow{\$}}$} & \multirow{7}{*}{ 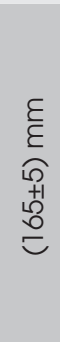 } & 11,98 & 3,14 & 3,03 & 12440,62 & 6,04 \\
\hline O & & & & 12,23 & 3,11 & 3,03 & 12000,70 & 6,05 \\
\hline $\begin{array}{l}\overline{\bar{g}} \\
\frac{\tau}{0}\end{array}$ & & & & 19,97 & 5,46 & 5,32 & 3963,11 & 10,62 \\
\hline $\begin{array}{l}0 \\
0 \\
0\end{array}$ & & & & 23,13 & 6,67 & 6,34 & 2520,18 & 12,65 \\
\hline 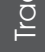 & & & & 23,42 & 6,92 & 6,56 & 2416,33 & 13,11 \\
\hline 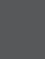 & & & & 25,50 & 7,65 & 7,20 & 1794,32 & 14,38 \\
\hline & & & & 26,63 & 8,11 & 7,65 & 1592,45 & 15,29 \\
\hline & & \multirow{3}{*}{$\underset{\sim}{\stackrel{\infty}{\sim}}$} & \multirow{3}{*}{$\begin{array}{l}\stackrel{\sigma}{0} \\
++1 \\
\stackrel{N}{N}\end{array}$} & 28,45 & 8,28 & 7,82 & 1175,57 & 15,62 \\
\hline & & & & 32,16 & 8,49 & 8,01 & 691,27 & 15,99 \\
\hline & & & & 34,81 & 9,45 & 8,93 & 472,80 & 17,83 \\
\hline & \multirow{4}{*}{$\begin{array}{l}\text { ? } \\
0 \\
11 \\
11 \\
0 \\
0\end{array}$} & \multirow{4}{*}{ 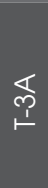 } & \multirow{4}{*}{$\begin{array}{l}\varepsilon \\
\varepsilon \\
0 \\
+1 \\
+1 \\
0 \\
ٍ\end{array}$} & 13,34 & 3,78 & 3,68 & 10232,54 & 7,34 \\
\hline & & & & 22,37 & 6,35 & 5,98 & 2809,86 & 11,94 \\
\hline & & & & 27,69 & 8,10 & 7,66 & 1311,75 & 15,29 \\
\hline & & & & 32,41 & 8,53 & 8,05 & 666,92 & 16,08 \\
\hline
\end{tabular}




\section{Table 5 - Suction test results for concrete test subjects}

\begin{tabular}{|c|c|c|c|c|c|c|c|c|}
\hline & \multirow{2}{*}{\multicolumn{2}{|c|}{ Data }} & & \multirow{2}{*}{$\begin{array}{c}\text { Paper filter's } \\
\text { gravimetricwater } \\
\text { content (\%) }\end{array}$} & \multicolumn{2}{|c|}{$\begin{array}{l}\text { Test subject's gravimetric water } \\
\text { content }(\%)\end{array}$} & \multirow{2}{*}{$\begin{array}{l}\text { Suction } \\
\text { (kPa) }\end{array}$} & \multirow{2}{*}{$\begin{array}{l}\text { Test subject's } \\
\text { volumetric } \\
\text { water } \theta(\%)\end{array}$} \\
\hline & & & & & Before & After & & \\
\hline \multirow{12}{*}{$\frac{0}{\frac{0}{00}}$} & \multirow{3}{*}{$\begin{array}{l}18 \\
0 \\
0 \\
11 \\
0 \\
0\end{array}$} & \multirow{3}{*}{$\underset{⿱}{\mathbb{I}}$} & \multirow{12}{*}{ 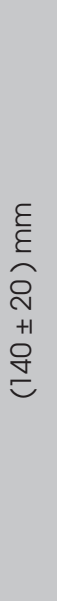 } & 28,17 & 4,65 & 4,54 & 1223,89 & 10,23 \\
\hline & & & & 47,07 & 7,36 & 7,16 & 79,73 & 16,12 \\
\hline & & & & 39,22 & 7,16 & 6,96 & 251,53 & 15,67 \\
\hline & \multirow{5}{*}{$\begin{array}{l}\llcorner \\
\text { L } \\
0 \\
11 \\
0 \\
0 \\
0\end{array}$} & \multirow{5}{*}{$\underset{\substack{\mathbb{1} \\
\vdash}}{\stackrel{1}{\vdash}}$} & & 21,90 & 4,71 & 4,54 & 3002,78 & 10,22 \\
\hline & & & & 41,67 & 7,26 & 7,04 & 177,15 & 15,85 \\
\hline & & & & 38,22 & 6,00 & 5,72 & 290,36 & 12,88 \\
\hline & & & & 35,74 & 6,72 & 6,45 & 414,17 & 14,53 \\
\hline & & & & 38,21 & 6,04 & 5,89 & 290,73 & 13,27 \\
\hline & \multirow{4}{*}{$\begin{array}{l}\stackrel{2}{f} \\
0 \\
11 \\
0 \\
0 \\
0\end{array}$} & \multirow{4}{*}{$\underset{\downarrow}{\downarrow}$} & & 20,57 & 5,29 & 5,20 & 3637,87 & 11,72 \\
\hline & & & & 48,64 & 7,63 & 6,79 & 73,49 & 15,30 \\
\hline & & & & 35,41 & 6,51 & 6,18 & 433,80 & 13,93 \\
\hline & & & & 33,13 & 6,19 & 6,04 & 601,87 & 13,60 \\
\hline
\end{tabular}

lar case for the concrete samples, although the obtained values show a greater dispersion, they are still proximate from one another. Hence, the water/cement mix relationship is not an influential factor. Kumar [12] used the vapor equilibrium method for the determination of water retention curves in manufactured concrete, having mix ratio values equal to $0.40,0.50$ and 0.60 . The results in this study suggest that similar profiles were obtained for all three concrete mixtures.

Figures 5 and 6 display the obtained results fitted according to Van Genunchten's [1] proposed model. Table 6 presents a summary for the model's parameters, obtained by the application of the Ordinary Least Squares method. LibreOffice ${ }^{\circledR}$ software spreadsheet was used to perform and adjust the curve fitting.

\section{Figure 3 - Retention curves obtained for mortar samples manufactured from traces T-1A, T-1B, T-2A, T-2B e T-3A}

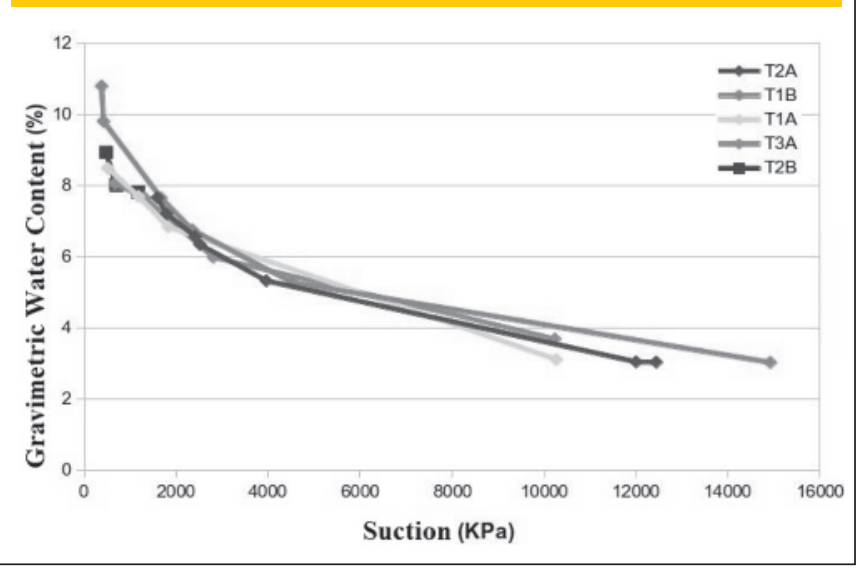

Hendrickx, Roels and Balen [13] acquired suctions values through the pressure plate method for cement and chalk samples. The materials' characteristics and their volumetric water content values for saturation $\left(\theta_{\mathrm{s}}\right)$, residual volumetric water content $\left(\theta_{\mathrm{r}}\right)$ and the permeability coefficient for saturation $\left(\mathrm{k}_{\mathrm{sat}}\right)$ are presented in table 7. Volumetric water content values $\left(\theta_{\mathrm{s}}=0,30\right.$ and $\left.\theta_{\mathrm{r}}=0,050\right)$ backup the parameters' results obtained for mortar samples presented in table 6.

According to Freitas, Torres and Guimarães [14], suction curve development relies on the distribution law, pores' radii and its variation. These researchers performed several tests to characterize degradation in Portuguese buildings in terms of the upward

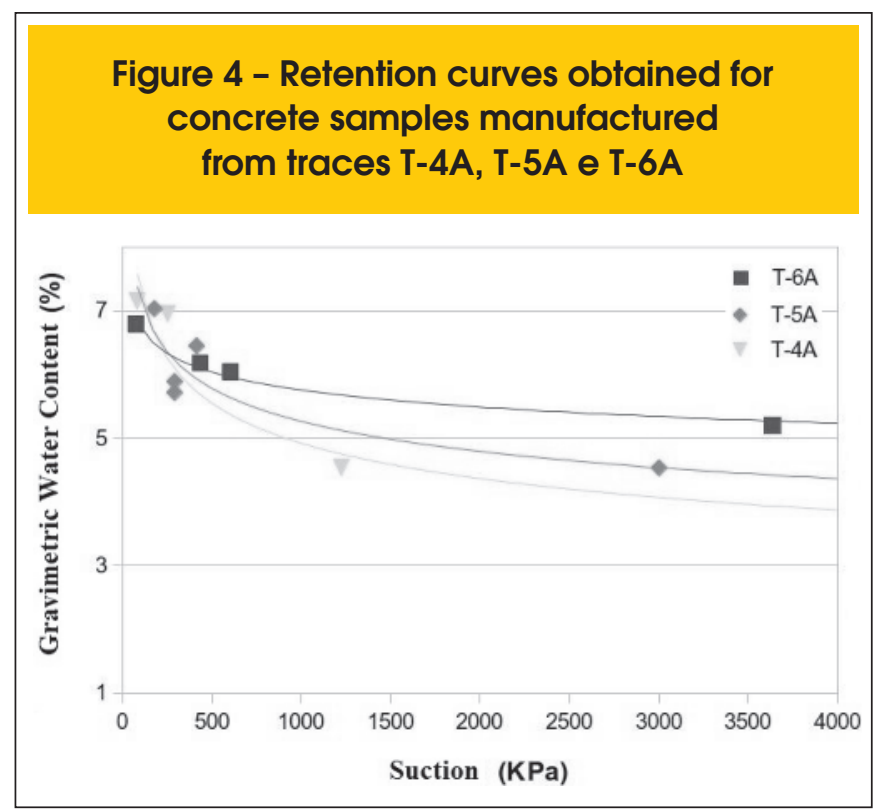


Filter paper method to determine the water retention curves for mortar and cement samples

Figure 5 - Correlation between suction and the volumetric water content for mortar samples, considering traces T-1A, T-1B, T-2A, T-2B and T-3A

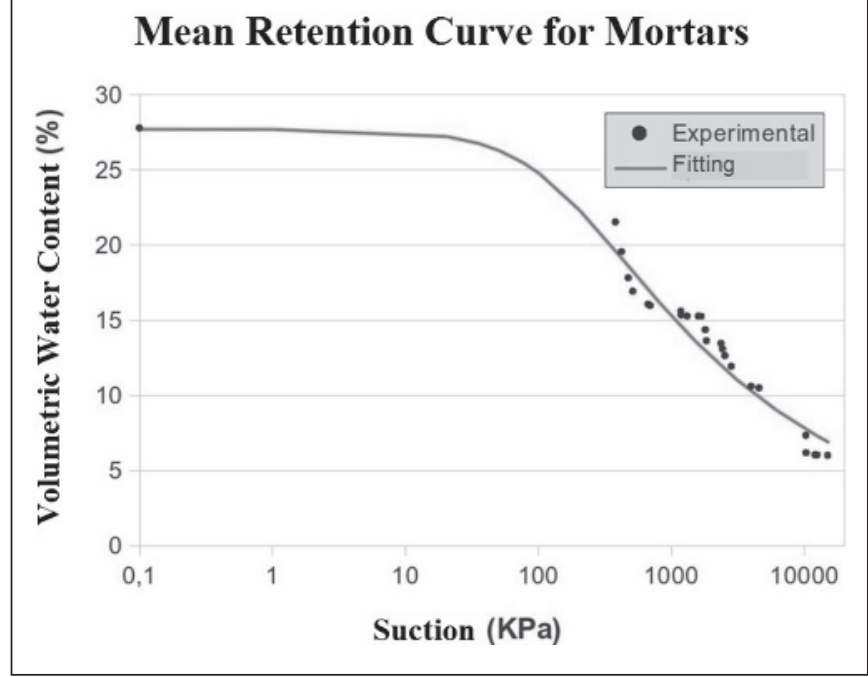

Figure 6 - Correlation between suction and the volumetric water content for concrete samples, considering traces $\mathrm{T}-4 \mathrm{~A}, \mathrm{~T}-5 \mathrm{~A}$ e T-6A

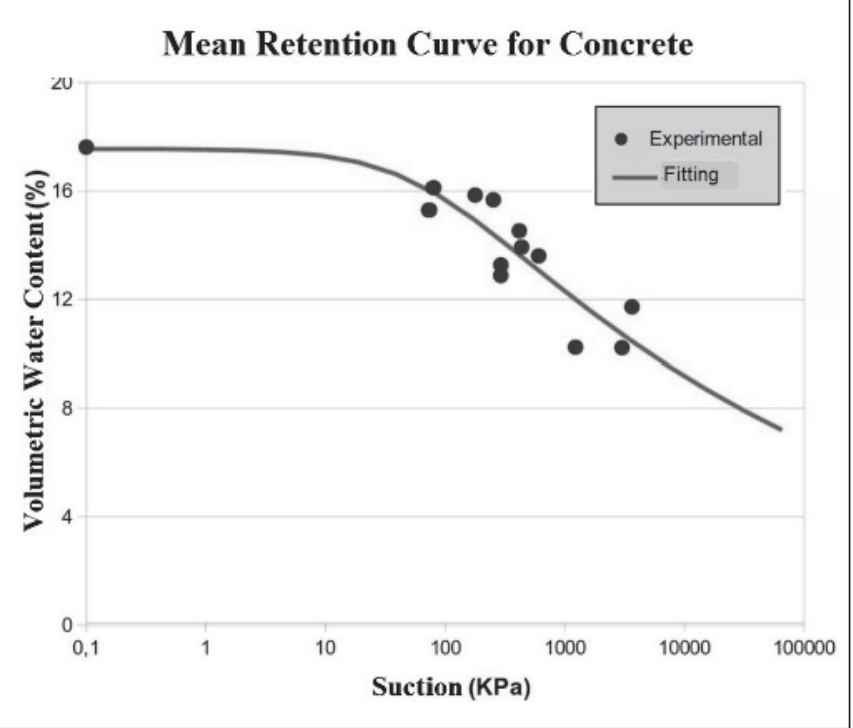

Table 6 - Fitting parameters ofthe water retention curves, according to the Van Genutchen (1) model, for mortars and concrete samples

\begin{tabular}{ccc} 
Paremeters & Mortars & Concretes (T-4A, T-5A e T-6A) \\
$\theta_{s}\left(\mathrm{~m}^{3} \cdot \mathrm{m}^{-3}\right)$ & $(\mathrm{T}-1 \mathrm{~A}, \mathrm{~T}-1 \mathrm{~B}, \mathrm{~T}-2 \mathrm{~A}, \mathrm{~T}-2 \mathrm{~B}$ e T-3A) & 0,17622 \\
$\theta_{\mathrm{r}}\left(\mathrm{m}^{3} \cdot \mathrm{m}^{-3}\right)$ & 0,27799 & 0 \\
$\mathrm{n}$ & 0 & 1,068775 \\
$\mathrm{~m}$ & 1,29634 & 0,06434 \\
\hline$\left(\mathrm{kPa}^{-1}\right)$ & 0,22859 & 0,0156045743 \\
$\mathrm{R}^{2}$ & 0,007066691 & $80,84 \%$ \\
\hline
\end{tabular}

Table7 - Composition, properties and parameters of suction for mortars manufactured from chalk or cement

\begin{tabular}{ccc} 
Data & \multicolumn{2}{c}{ Mortars } \\
\hline Binder/Sand $(\mathrm{kg} / \mathrm{kg})$ & Chalk & Cement \\
Water/Binder $(\mathrm{kg} / \mathrm{kg})$ & 0,112 & 0,218 \\
\hline Binder's specific surface area $\left(\mathrm{m}^{2} / \mathrm{g}\right)$ & 2,016 & 0,907 \\
\hline Binder's particle average diameter $(\mu \mathrm{m})$ & 12,0 & 1,30 \\
$\theta_{\mathrm{s}}\left(\mathrm{m}^{3} \cdot \mathrm{m}^{-3}\right)$ & 6,03 & 12,50 \\
$\theta_{\mathrm{r}}\left(\mathrm{m}^{3} \cdot \mathrm{m}^{-3}\right)$ & 0,33 & 0,30 \\
$\mathrm{k}_{\mathrm{sat}}(\mathrm{m} / \mathrm{s})$ & 0,130 & 0,050 \\
Source: Hendrickx, Roels and Balen $(14)$ & $2,27 \times 10^{-7}$ & $6,17 \times 10^{-7}$ \\
\hline
\end{tabular}




\section{Figure 7 - Retention curve obtained from different porous materials}

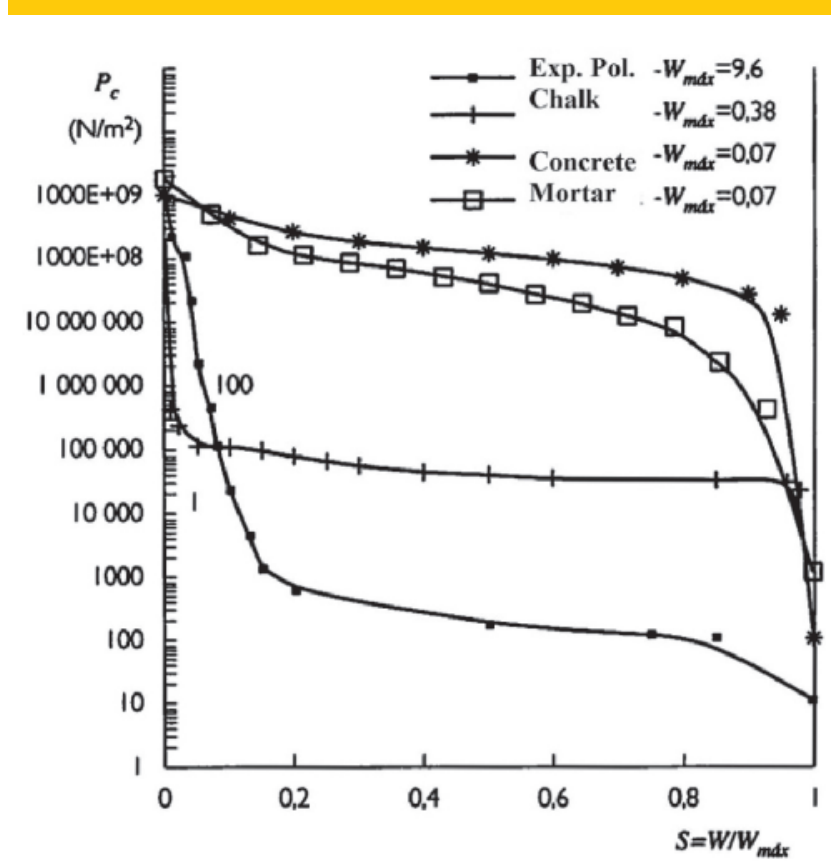

Source: Freitas, Torres and Guimarães (14).

humidity originated from the soil, due to the capillary effect occurring through the materials' pores that form the building's walls and floors. Figure 7 shows the retention curves obtained for different materials (concrete, mortar, chalk and expanded polyurethane).

\section{Conclusions}

The total suction results obtained through the paper filter method using the mortar and concrete samples, display no significant influence from the water/cement proportions in this particular phenomenon. Considering the $27.80 \%$ volumetric water content for mortars and $17.62 \%$ for concrete samples, the minimum suction values obtained for these materials were $50 \mathrm{~Pa}$ and $100 \mathrm{~Pa}$, respectively. Regarding the fitting parameters for the materials' retention curves, when compared to those obtained for soils, a great discrepancy is witnessed, caused by the distinctive porous characteristics that exist amongst these materials. In general, the water retention curves obtained for concrete samples are more similar to those obtained for clayey soils, capable of retaining significant volumes of water for high suction values (see Figure 1).

Regardless of the few data available in literature, values obtained in this study for the volumetric water content during saturation and residual processes $\left(\theta_{\mathrm{s}}=0.30\right.$ and $\left.\theta_{\mathrm{r}}=0.050\right)$ are proximate to those provided by other authors.

Consequently, this study confirms the usage of an unconventional procedure as successful; therefore, the obtained values were satisfactory, reason to suggest the implementation of these values in more suitable simulations, using specific surrounding conditions.

\section{References}

[1] VAN GENUCHTEN, M. Th. A Closed Form Equation for Predicting the Hydraulic Conductivity of Unsaturated Soils. Soil Science, Society of America Journal, Madison, WI, 44:5, p. 892-898, 1980.

[2] MACHADO, S. L.; PRESA, E. P. Current Tendencies for Unsaturated Soils in Brazil. ECOS do NSAT 2007. In: BRAZILIAN CONGRESSFOR SOIL MECHANICS AND GEOTECHNICAL ENGINEERING - COBRAMSEG, 2008, Búzios, RJ. Anais... Vol., p.231-250.

[3] BRAZILIAN ASSOCIATION OF TECHNICAL NORMS. NBR 9779: mortar and harden concrete-water absorption determination through capillarity. Rio de Janeiro, 1995. 2 p.

[4] PRESA, E. P. Expansive Clay misshape under controlled suction. 1982. Doctoral Thesis- Escuela Técnica Superior de Ingenieros de Caminos, Canales y Puertos, Universidad Politécnica de Madrid, Madrid.

[5] FREDLUND, D. G.; XING, A. Equations for the soil water characteristic curve. Canadian Geotechnical Journal, Ottawa, 31- 4, p. 521-532, 1994.

[6] MUALEM, Y. A new model for predicting the hydraulic conductivity of unsaturated porous media. Water Resources Research, 12-3, p. 513-522, 1976.

[7] AMERICAN SOCIETY FOR TESTING AND MATERIALS ASTM. ASTM D5298 -10: Standard test method for measurement of soil potential (suction) using filter paper. In:

Annual Book of ASTM Standards. vol. 15.09. Philadelphia, 2010.

[8] SILVA, A. M. Water Retention Curve for Brazilian soils. 2005. Thesis (Civil Engineering Master's Program) - Escola de Engenharia de São Carlos, Universidade Estadual de São Paulo, USP, São Carlos, SP.

[9] BRAZILIAN ASSOCIATION OF TECHNICAL NORMS. NBR 7215: Portland Cement-resistance and compression determination. Rio de Janeiro, 1996. 8 p.

[10] BRAZILIAN ASSOCIATION OF TECHNICAL NORMS. NBR 5738: Cylindrical test subject's molding and curing; procedure. Rio de Janeiro, 2008. 6 p.

[11] CHANDLER, R. J.; GUTIERREZ, C.I. (1986). The Filter-Paper Method of Suction Measurement. Géotechnique, Vol. 36, $\mathrm{N}^{\circ} 2$, p. 265-268.

[12] KUMAR, A. Water flow and transport of chloride in unsaturated concrete. A thesis submitted to the college of graduate studies and research in partial fulfilment the degree of master of science in the Department of Civil and Geological Engineering, University of Saskatchewan, Saskatoon, Canada, 2010.

[13] HENDRICKX, R.; ROELS, S.; BALEN, K.V. Measuring the water capacity and transfer properties of fresh mortar. Cement and Concrete Research, New York, v. 40, p.1650 $-1655,2010$.

[14] FREITAS, V. P; TORRES, M. I; GUIMARÃES, A. S. Humidade Ascensional. Porto: FEUP, 2008. 106 p. 